\title{
Pathogenic Puppetry: Manipulation of the Host Actin Cytoskeleton by Chlamydia trachomatis
}

\author{
Liam Caven ${ }^{1,2}$ and Rey A. Carabeo ${ }^{2, *}$ \\ 1 School of Molecular Biosciences, Washington State University, Pullman, WA 99164, USA; \\ liam.caven@wsu.edu \\ 2 Department of Pathology and Microbiology, University of Nebraska Medical Center, \\ Omaha, NE 68198-5900, USA \\ * Correspondence: rey.carabeo@unmc.edu; Tel.: +1-402-836-9778
}

Received: 4 December 2019; Accepted: 19 December 2019; Published: 21 December 2019

\begin{abstract}
The actin cytoskeleton is crucially important to maintenance of the cellular structure, cell motility, and endocytosis. Accordingly, bacterial pathogens often co-opt the actin-restructuring machinery of host cells to access or create a favorable environment for their own replication. The obligate intracellular organism Chlamydia trachomatis and related species exemplify this dynamic: by inducing actin polymerization at the site of pathogen-host attachment, Chlamydiae induce their own uptake by the typically non-phagocytic epithelium they infect. The interaction of chlamydial adhesins with host surface receptors has been implicated in this effect, as has the activity of the chlamydial effector TarP (translocated actin recruitment protein). Following invasion, C. trachomatis dynamically assembles and maintains an actin-rich cage around the pathogen's membrane-bound replicative niche, known as the chlamydial inclusion. Through further induction of actin polymerization and modulation of the actin-crosslinking protein myosin II, C. trachomatis promotes egress from the host via extrusion of the inclusion. In this review, we present the experimental findings that can inform our understanding of actin-dependent chlamydial pathogenesis, discuss lingering questions, and identify potential avenues of future study.
\end{abstract}

Keywords: actin cytoskeleton; chlamydia; bacterial pathogenesis

\section{Introduction}

The cytoskeleton is a highly dynamic structural framework composed of actin, microtubules, intermediate filaments, and septins. Restructuring of the cytoskeleton's actin component is critical for a variety of cellular processes, including endocytosis, motility, nutrient acquisition, and mitosis. It should therefore be unsurprising that modulation of the actin structure and function is a common theme amongst intracellular and extracellular pathogenic bacteria: by manipulating the cytoskeleton, these organisms can induce their own uptake by host cells, scavenge nutrients from host organelles, and ultimately establish a niche that facilitates their own replication.

The structure of the actin cytoskeleton is dynamically regulated by the recruitment of actin-polymerizing (or depolymerizing) factors, which consequently alter the balance of monomeric/globular actin (G-actin) and filamentous actin (F-actin) in the cytosol. Nucleation of a new actin filament requires the formation of a thermodynamically unfavorable actin trimer; to bypass this requirement, the Arp2/3 (actin-related protein) complex recruits a single G-actin monomer alongside two structural analogs to form a site of nucleation [1-3]. Subsequent F-actin branching by Arp $2 / 3$ is regulated by nucleation promotion factors (NPFs), such as N-WASP, SCAR/WAVE, and WASH [4,5]. The binding of NPFs to G-actin (Type I) or F-actin (Type II) facilitates conformational changes in Arp2/3 that enhance the complex's F-actin branching activity. NPF activation is in turn 
regulated by the Rho family GTPases RhoA-C, Rac1, and Cdc42-all of which are targets for modulation by pathogens seeking to restructure actin and thereby facilitate pathogenesis $[6,7]$.

The manipulation of host actin can promote a wide variety of beneficial outcomes for the pathogen. Salmonella spp. translocate the effectors SopE and SopE2 into host cells-these guanine exchange factor (GEF) mimics enhance the activity of Rac1 and Cdc42, creating localized concentrations of F-actin at the apical surface of mucosal epithelia [8-11]. The result is extensive ruffling of the plasma membrane at the site of Salmonella attachment, leading to internalization of the pathogen via micropinocytosis [8,12-14]. Upon internalization and escape into the host cytosol, the Gram-positive intracellular pathogen Listeria monocytogenes induces the polymerization of actin on the bacterial surface through the activity of ActA, a surface protein functionally analogous to the nucleation promotion factor WASP [15]. ActA recruits an Arp2/3 complex to the bacterial pole, resulting in branched actin polymerization producing a comet-shaped structure that propels Listeria across the cytosol and into adjacent uninfected cells [16-20].

Indeed, this dynamic can be observed even in non-invasive bacterial pathogens. Enteropathogenic and enterohemorrhagic E. coli (EPEC/EHEC) induce the formation of distinctive, actin-rich pedestals that facilitate their attachment to gastric epithelia. The virulence factor Tir is responsible for this effect: upon delivery into host cells by the E. coli type III secretion system (T3SS), Tir is incorporated into the plasma membrane, promoting EPEC/EHEC attachment via binding to the bacterial adhesin intimin [21,22]. This clusters Tir at the site of attachment, inducing the phosphorylation of Tir's cytosolic domain by host kinases and the subsequent recruitment of Nck $[23,24]$. Nck is an adaptor protein that binds and activates N-WASP - consequently, the downstream effect of the Tir/Nck interaction is the recruitment of N-WASP and Arp2/3 complexes at sites of EPEC/EHEC attachment [25]. The resulting polymerization of branched actin produces pedestal formation, effacing the microvillar structure of the gastric mucosa and facilitating EPEC/EHEC colonization of the gastrointestinal tract $[26,27]$.

The Gram-negative Chlamydia spp. constitute a valuable model for the study of actin modulation by bacterial pathogens. As obligate intracellular parasites, Chlamydia trachomatis and related species restructure actin in a variety of ways, to facilitate host invasion, maintain their replicative niche, and egress from host epithelial cells. Multiple $C$. trachomatis serovars have been isolated with distinct tissue tropism in the host: serovars A-C infect the conjunctival epithelium (producing the species' eponymous fibrotic trachoma), whereas serovars D-K and L1-L3 colonize the urogenital and anogenital tracts, respectively $[28,29]$. This extensive tissue tropism demonstrates a capability to modulate actin in multiple epithelial cell types, further borne out by the observation of pathogen-directed actin rearrangement by the respiratory pathogen C. pneumoniae [30,31], as well as the mouse- and guinea pig-infecting C. muridarum and C. caviae [32-34]. The study of chlamydial pathogenesis thus has the potential to reveal striking insight into both the pathogenic and steady-state regulation of actin in the host. In this review, we will summarize the field's current understanding of actin modulation by Chlamydiae both during and after host invasion, as well as discuss potential avenues of further research.

\section{A Multilayered Assault: Chlamydia Redistributes the Actin Cytoskeleton to Invade Host Cells}

The initial study of chlamydial invasion emphasized the importance of actin recruitment at sites where the infectious form of Chlamydiae (the elementary body, or EB) adheres to the host cell surface $[35,36]$. This early observation of in vitro infections occurred concomitant with the formation of microvillar structures that surround (and presumably internalize) invading Chlamydia [36,37]. The pharmacological disruption of F-actin (via cytochalasin D) or sequestration of G-actin (via latrunculin B) substantially inhibits chlamydial invasion and microvillar formation, suggesting that actin polymerization (not simply recruitment) is critical to fostering entry of the pathogen [35-37]. Furthermore, live-cell imaging of invasion events after cytochalasin D washout revealed the selective reestablishment of microvilli sites of EB attachment, indicating that this phenomenon is highly specific and pathogen-directed [36]. Clearly, the attachment of Chlamydia to the host cell surface is a critical first step to invasion, but how does EB attachment lead to actin rearrangement in the host? Extensive 
study of chlamydial invasion over the past two decades has suggested two, likely complementary, mechanisms: first, the engagement of host receptors by chlamydial adhesins facilitates the induction of actin polymerization indirectly, and second, bacterial effectors delivered by Chlamydia into the host remodel the actin cytoskeleton directly. The findings underlying these hypotheses are reviewed in the following sections.

\subsection{Actin Modulation during Transient Chlamydial Adhesion}

An early observation of $C$. trachomatis infections in vitro was that host attachment appeared to occur in two distinct stages: a reversible and temperature-insensitive interaction, followed by irreversible adhesion that requires physiological temperature [38-40]. Initial, transient EB attachment has since been shown to be an electrostatic interaction mediated by the glycosaminoglycan (GAG) heparan sulfate [41,42]. Heparan sulfate is demonstrably required for invasion by chlamydial serovars L1-L3, with other serovars exhibiting varying levels of GAG requirement $[38,43]$. Produced by a variety of cell types, heparan sulfate exhibits a strong negative charge that permits its binding to bacterial surface proteins; indeed, an early proposed mechanism for EB attachment posited the formation of a tripartite "molecular bridge" between heparan sulfate and host/bacterial GAG-binding proteins [44-47]. The bacterial surface protein OmcB is considered the primary GAG-binding protein in serovars whose adhesion is dependent on heparan sulfate [48-50]. OmcB has been shown to bind the alternative GAG heparin in vitro, and exhibits a variant amino acid sequence in the GAG-independent serovar E [50]. The chlamydial major outer membrane protein (MOMP) of C. muridarum has also been shown to bind GAGs to mediate invasion: treating host cells with recombinant MOMP or OmcB markedly reduces EB-host binding, as does treatment with monoclonal antibodies against $C$. muridarum MOMP [51].

The host component of this GAG-mediated bridge between EB and the host has remained elusive; however, recent work suggests an alternative, GAG-independent OmcB/MOMP attachment mechanism. Mounting evidence indicates that both proteins are post-translationally modified via glycosylation, as OmcB/MOMP recovered from EBs shows evidence of modification by N-linked high-mannose oligosaccharides [52-54]. Furthermore, both proteins exhibit reactivity to Erythrina crista-galli lectin, which binds to sites of $\mathrm{N}$-acetyllactosamine glycosylation [54]. It has been further shown that glycosylated OmcB and MOMP are recognized by the protein galectin-1 (Gal1), which is both secreted by the host and bound on the plasma membrane to surface receptors [54]. Given that galectin-1 can demonstrably bridge EBs to host Gal1 receptors [54], both its secreted and membrane-associated state could conceivably facilitate EB-host binding. However, the latter state presents an intriguing avenue for the chlamydial induction of actin recruitment and invasion: in neurons, surface-associated Gal1 has been shown to initiate clathrin-independent endocytosis upon ligand binding, and Gal1 internalization is associated with F-actin polymerization during axonal growth [55].

A clathrin-independent mechanism of chlamydial invasion is of particular interest, given that clathrin's role in chlamydial invasion is somewhat controversial. In 1999, Boleti et al. assessed the importance of clathrin-mediated endocytosis to invasion via the expression of a dominant negative mutant of Eps15 [56]. Eps15 interacts with the clathrin adaptor protein AP-2 at clathrin-coated pits [57,58]; ablating this interaction thus inhibits clathrin-mediated endocytosis [59,60]. Importantly, the invasion of both $C$. trachomatis serovar L2 and C. caviae was unaffected by the expression of dominant negative Eps15, suggesting that clathrin is largely dispensable for chlamydial invasion [56]. However, a more recent study involving RNAi-mediated clathrin knockdown during serovar L2 infection presented a small (but statistically significant) invasion defect [61]. A likely explanation for these conflicting results is that Chlamydia employs multiple, functionally redundant mechanisms of invasion, each of varying clathrin dependence. The interaction of OmcB and MOMP with surface-associated Gal1 may enhance clathrin-independent invasion, either by other adhesin-receptor binding or the action of chlamydial effectors. Experiments studying invasion in galectin-knockout cells are therefore warranted, in order to assess the relative importance of this interaction to chlamydial invasion generally, and its potential role in actin recruitment specifically. 


\subsection{Actin Modulation during Irreversible Chlamydial Attachment}

Irreversible, temperature-sensitive attachment of Chlamydia to the host is the result of bacterial adhesin binding to specific host receptors. Indeed, the study of chlamydial invasion has identified an extensive portfolio of host and bacterial proteins that promote attachment (reviewed in more detail by Romero et al. [62]). Of these, several host receptors bound by Chlamydiae promote actin recruitment and endocytosis elsewhere, suggesting their possible role in the pathogen's modulation of the actin cytoskeleton (Figure 1). For example, C. trachomatis serovar E and C. muridarum have been shown to directly bind the fibroblast growth factor (FGF), enabling molecular bridge formation between EBs and the host FGF receptor (FGFR) [63]. Intriguingly, the engagement of FGF-bound EBs with FGFR activated downstream signaling: phosphorylation of the FGFR substrate and docking protein FRS2 $\alpha$ was increased by infection, and phosphorylated FRS2 $\alpha$ was recruited to sites of EB attachment [63]. Typical binding of FGFR to its ligand results in internalization of the ligand-receptor complex, via Src/Eps8-dependent, clathrin-mediated endocytosis [64]. The involvement of Src is particularly significant, given that the kinase has been implicated in the recruitment of Rac1, WAVE, and Arp2/3 by the chlamydial invasion effector TarP (described below). Taken together, these observations suggest that Chlamydia-mediated activation of FGFR may aid in the recruitment of Src to the site of invasion.

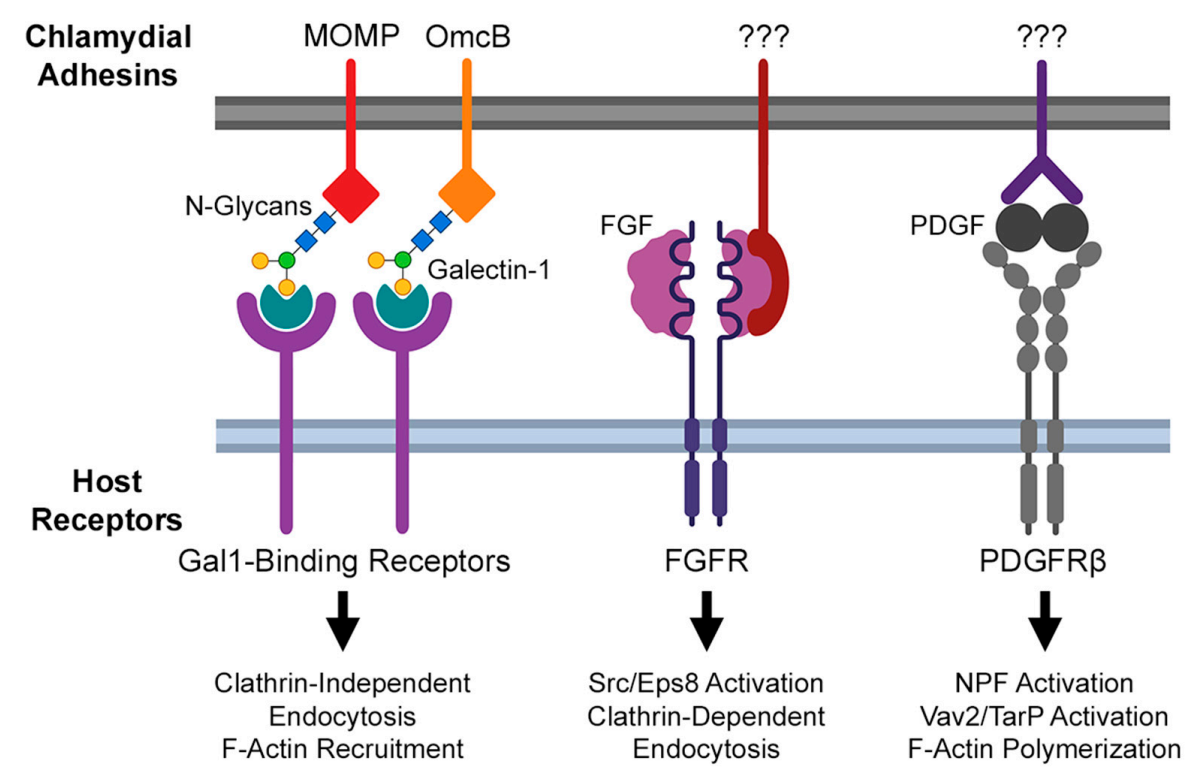

Figure 1. Summary of known chlamydial adhesin/host receptor interactions implicated in Chlamydia-directed modulation of actin.

An RNA interference screen of host factors contributing to invasion by C. muridarum identified the beta-isoform of the platelet-derived growth factor receptor (PDGFR $\beta$ ) as another target of chlamydial attachment [33]. Much like FGFR, PDGFR $\beta$ is activated by EB binding and thereby promotes the tyrosine phosphorylation of multiple actin-modulatory proteins previously implicated in chlamydial invasion, including the nucleation promoting factors (NPFs) WAVE2 and cortactin, the Rac1 activator Vav2, and the chlamydial invasion effector TarP [33]. However, PDGFR $\beta$ activation was found to be dispensable for invasion, due to a compensatory mechanism dependent on activation of the Abelson (Abl) family of kinases [33]. This result suggests that PDGFR $\beta$ and Abl are elements of complementary invasion pathways, likely acting through a TarP-dependent mechanism given previous data linking TarP function to Vav2 and Abl (see below). Ultimately, a more thorough understanding of underlying mechanisms of each pathway is required, of which an essential first step is the identification of chlamydial factors that bind PDGFR $\beta$ or activate Abl kinases. Recent advances in Chlamydia transposon mutant strains may enable further study in this area, as would the use of Abl/PDGFR $\beta$-deleted host cell lines generated via CRISPR/Cas9. Regardless, the substantial variety of host receptors 
with which invading EBs can interact suggests that Chlamydiae rely upon multiple host signaling pathways to mediate invasion; given the non-phagocytic nature of host cells, chlamydial modulation of those pathways thus maximizes the invasion efficiency. Ongoing study in organoid and in vivo models of $C$. trachomatis infection may better illustrate the relative contribution of each pathway to chlamydial invasion.

\subsection{TarP, a Multifunctional Actin-Recruiting Effector}

As noted previously, the invasion of host cells by EBs occurs concomitantly with extensive tyrosine phosphorylation of proteins at the site of EB attachment [65-67]. Pulldown of these species by tyrosine phosphoantibodies and subsequent characterization revealed the presence of a bacterial effector, now known as TarP (translocated actin recruitment protein) [67]. TarP has since been shown to be translocated into the host cytosol by the chlamydial T3SS, where it has a multifunctional role in facilitating actin polymerization and subsequent internalization of the pathogen. TarP has been repeatedly implicated in the invasion of $C$. trachomatis and is highly conserved amongst all Chlamydia species with sequenced genomes [34,68], emphasizing a critical role for this effector in chlamydial pathogenesis.

The structure and functional domains of TarP can be divided into C- and N-terminal halves (Figure 2). The C-terminal domains are highly conserved amongst C. trachomatis serovars and other Chlamydiae [34], containing a proline-rich domain (PRD), an actin-binding domain (ABD), a leucine-aspartate (LD) motif that binds focal adhesion kinase (FAK), and a vinculin-binding domain (VBD). At sites of EB attachment and engagement of the chlamydial T3SS, the TarP PRD allows translocated TarP molecules to oligomerize [69]. This is presumed to create a high local concentration of ABD-bound actin at the invasion site, likely facilitating the formation of a trimeric actin nucleus for subsequent F-actin polymerization (Figure 3A) [69]. By contrast, the LD and VBD domains of TarP stimulate actin polymerization indirectly. Recruitment of the signaling kinase FAK by the TarP LD induces actin remodeling in an Arp2/3-dependent fashion (Figure 3B) [70]. Binding of the VBD to the actin adaptor protein vinculin promotes F-actin recruitment, which leads to further actin polymerization via an uncharacterized mechanism (Figure 3C) [71].

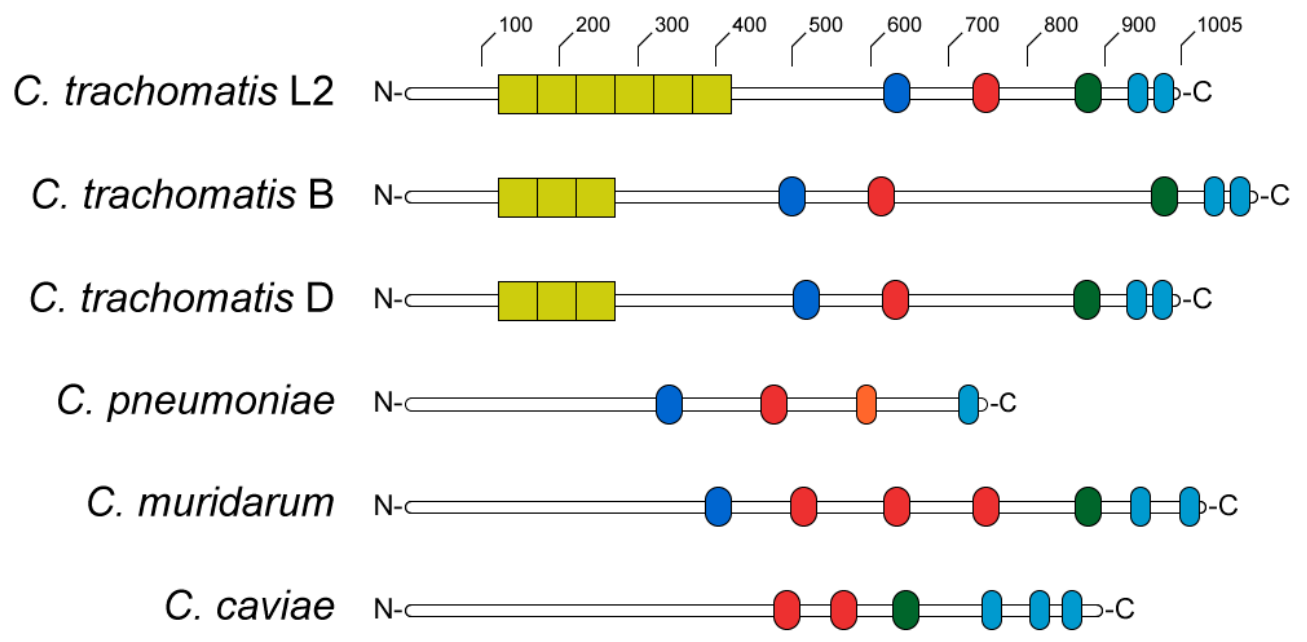
Tyr-Phosphodomain
Proline-Rich Domain (PRD)
G-Actin Binding Domain (ABD)
F-Actin Binding Domain
FAK-Binding LD Motif (LD)
Vinculin Binding Domain (VBD)

Figure 2. Diagram of TarP homologs in anogenital (L2), ocular (B), and genital (D) serovars of Chlamydia trachomatis, as well as C. pneumoniae, C. muridarum, and C. caviae. 


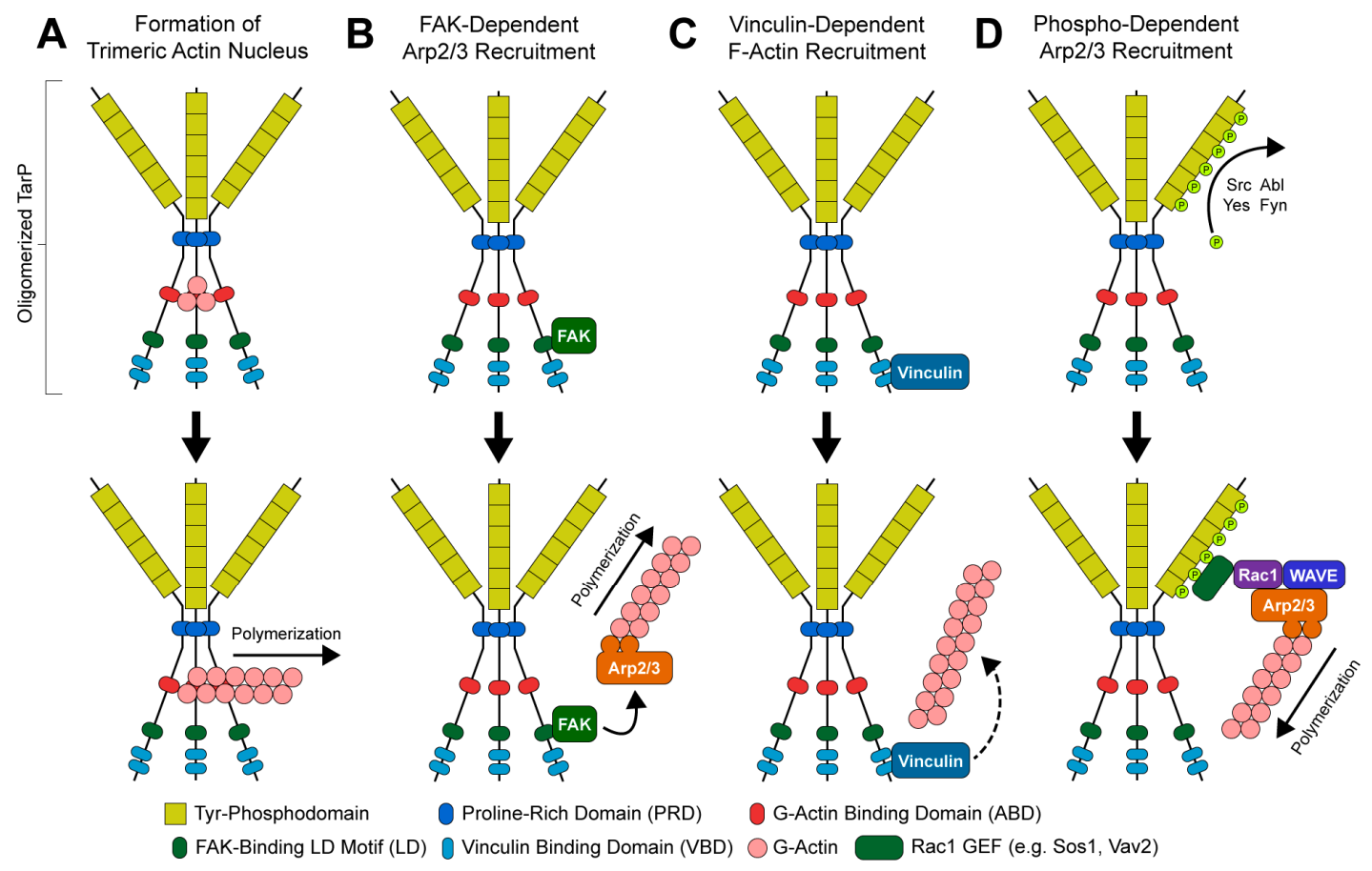

Figure 3. Mechanisms of TarP-directed actin modulation: (A) oligomerization-dependent formation of trimeric actin nucleus; (B) focal adhesion kinase (FAK)-dependent recruitment of the Arp2/3 complex; (C) vinculin-dependent recruitment of F-actin; (D) phosphorylation-dependent recruitment of an Arp2/3-activating protein complex.

Intriguingly, the complex of host and chlamydial proteins recruited at the invasion site bears substantial similarity to a focal adhesion-A membrane-associated protein complex that couples the actin cytoskeleton to the extracellular matrix (ECM). Focal adhesions are assembled in an FAK- and Src-dependent fashion around the cytosolic domain of ECM-bound integrins [72-76], subsequently recruiting F-actin stress fibers to play an important role in host cell motility and signaling [77]. The resemblance of the chlamydial invasion complex to the focal adhesion is supported by a number of additional observations: the focal adhesion component paxillin is also recruited at sites of EB invasion, the invasion efficiency is markedly decreased during C. caviae infection of FAK- or vinculin-knockout MEFs, and an interaction between the chlamydial surface protein Ctad1 and host integrin- $\beta 1$ supports the adhesion of $C$. trachomatis serovar $E$ to host cells in vitro [71,78]. Given the predominantly basolateral localization of integrins in the polarized epithelial cells Chlamydiae typically infect, access to integrin- $\beta 1$ receptors would require the disruption of intercellular junctions via micro-abrasions in the epithelium or loss of apicobasolateral polarity, as occurs during documented the epithelial-to-mesenchymal transition (EMT) of Chlamydia-infected epithelial cells [79]. The functional consequences of the recruitment of a focal adhesion-like structure to the site of chlamydial invasion of polarized cells are largely unexplored. Additionally, given that TarP expression is detectable between 8 and $18 \mathrm{~h}$ post-infection (hpi)—Long after invasion, but before the differentiation of infectious EBs-The possibility that this effector may have a post-invasion role modulating FAK- or vinculin-containing structures in the host is difficult to ignore [80].

The N-terminal half of $C$. trachomatis TarP contains between one and twelve copies of a tyrosine phosphodomain, with the copy number varying by serovar (Figure 2) $[34,67,68,81,82]$. This domain exhibits a high sequence similarity to targets of Src- and Abl-family kinases; accordingly, p60-Src, Yes, Fyn, and Abl are capable of phosphorylating TarP in vitro [83]. A variety of host proteins have been shown to interact with the TarP N-terminus upon its phosphorylation, including two guanidine exchange factors (Sos1 and Vav2) that enhance the activity of the GTPase Rac1 [84]. Rac1 activation by TarP subsequently initiates actin branching and polymerization, via the Rac1- and WAVE-dependent 
recruitment of an Arp2/3 complex (Figure 3D) [84,85]. Additionally, it has been demonstrated that the recruitment of Arp2/3 may enhance the actin-nucleating function of TarP's C-terminal domains: the same in vitro pyrene-actin assay that established this function of TarP exhibited enhanced actin polymerization when Arp2/3 complexes were added [69]. The prevailing interpretation of this result is that the PRD/ABD domains and phosphodomains of TarP act in concert: the PRD and ABD domains promote the formation and extension of an initial (mother) actin filament, while the phosphodomains recruit Arp2/3 to facilitate branching from the mother filament.

The study of TarP has generally focused upon the C. trachomatis serovar homologs of the protein; perhaps unsurprisingly, characterization of the TarP orthologs has substantially complicated our understanding of the effector's various functions. C. muridarum and C. caviae possess TarP orthologs absent of any phosphodomains [34], suggesting that TarP phosphorylation is largely dispensable for the invasion of mouse and guinea pig epithelial cells. Additionally, recent functional characterization of the C. pneumoniae TarP homolog CPn0572 has revealed an alternative actin-modulating function: CPn0572 expressed in HEK293T cells exhibited an alternative localization pattern to that of TarP, associating with F-actin filaments projecting from the actin-rich aggregates where TarP is typically observed [31]. When ectopically expressed in yeast, CPn0572 promotes the increased incidence of short F-actin bundles [30,31], which may be reminiscent of the F-actin bundles formed by $C$. trachomatis TarP [86]. This effect is dependent on the CPn0572 VBD, as well as a novel domain that binds F-actin (in contrast to the G-actin-binding TarP/CPn0572 ABD) [30]. Furthermore, CPn0572 binding displaces the actin depolymerizing factor cofilin, suggesting that CPn0572 promotes the formation of actin bundles indirectly by inhibiting their disassembly [31]. The purpose of these structures to C. pneumoniae invasion is unclear, though cofilin and cofilin-displacing effectors have been implicated in the invasion of other intracellular pathogens $[87,88]$.

The TarP orthologs of C. pneumoniae, C. muridarum, and C. caviae have the potential to provide critical insight into how requirements for the induction of phagocytosis differ, depending on the host tissue type (genital/ocular vs. pulmonary epithelium) or host organism (human vs. murine). Heterologous complementation of virulence factors has been used to interrogate the mechanism of host tropism for other pathogens. However, the relative intractability of Chlamydia to genetic manipulation generally and TarP knockout specifically has hitherto precluded this approach [89]. The recent development of Chlamydia conditional expression/knockout strains may enable the use of this method [90,91], thereby illustrating the relative contribution of TarP's many actin-modulating functions to invasion.

While the field's understanding of TarP's functional domains is extensive, the mechanism by which TarP translocation is regulated by pathogen adhesion to host cells remains somewhat unclear, beyond a presumed dependence on the activity of the chlamydial type III secretion system. In the Gram-negative pathogen Yersinia pestis, activation of the type III secretion system is cell contact-dependent, and possibly mediated by the YopN-TyeA-YscB-SycN complex-termed the calcium plug due to the complex's calcium-dependent restriction of effector secretion in a cell-free context [92]. Only one complex member has been identified in Chlamydia: CopN (homologous to YopN) [93]. However, the chlamydial T3SS exhibits a similar sensitivity to calcium-mediated inhibition-indeed, Jamison and Hackstadt observed that $\mathrm{Ca}^{2+}$ chelation by EGTA was required for cell-free chlamydial effector translocation to occur [94]. Cell-free TarP translocation by chlamydial EBs is demonstrably induced by cholesterol and sphingomyelin-enriched liposomes [94], which suggests a contact-dependent model of T3SS activation dependent on specific lipids. We refer the reader to reviews from Betts-Hampikian, Ferrell, and Fields for a comprehensive discussion of the chlamydial T3SS [95,96].

The field's current understanding of TarP's various functions indicates that this effector serves as a signaling scaffold, targeting host actin-remodeling machinery to the site of chlamydial invasion. The potential of TarP to nucleate actin likely serves to enhance the actin-dependent invasion of non-phagocytic cell types. It is possible that invasion is mechanistically linked with the nascent Chlamydia-containing vacuole's subsequent evasion of fusion with bactericidal host lysosomes, as 
has been observed with other intracellular pathogens. For example, recruitment of the small GTPase Rab5 to the vesicular surface during infection by Brucella abortus has been implicated in trafficking of the Brucella to a hospitable intracellular compartment; critically, Rab5 recruitment has been observed concomitant with invasion, during invagination of the clathrin-coated Brucella-containing vesicle [97]. The action of TarP and other actin-modulating effectors may similarly promote trafficking to a pathogen-favorable environment-elucidating the mechanistic connection between the invasion and chlamydial modulation of endocytic machinery is thus an intriguing topic for further study.

\subsection{Actin-Depolymerizing Chlamydial Effectors}

It is important to note that the induction of actin polymerization and bundling is not a terminal state for chlamydial invasion. After restructuring the cytoskeleton to initiate endocytosis, it is then necessary to restore steady-state actin dynamics in the host for invasion to proceed. Multiple candidates for this function have been identified in Chlamydiae-one such example is the $C$. trachomatis protein TmeA, a T3SS effector shown to associate with host AHNAK by a yeast two-hybrid assay $[98,99]$. AHNAK is a ubiquitous phosphoprotein implicated in cortical actin maintenance [100]; specifically, a C-terminal fragment of the protein has been shown to induce F-actin bundling [101]. Accordingly, the ectopic expression of TmeA in HeLa cells produced striking morphological changes consistent with the redistribution of actin [98]. This implies that TmeA may relieve the actin-bundling effects of TarP after invasion has begun; however, further study has complicated our understanding of TmeA's true role in pathogenesis.

A recent report by McKuen et al. adds more nuance to the relationship between TmeA and AHNAK [102]. While TmeA can recruit AHNAK to the site of invasion and inhibit AHNAK-mediated actin bundling in vitro, $C$. trachomatis invasion of AHNAK-knockout mouse embryonic fibroblasts (MEFs) had no invasion defect relative to that of wild-type cells [102]. Combined with the reported AHNAK-independent invasion defect in a TmeA-knockout $C$. trachomatis strain, these results suggest that TmeA facilitates invasion via an unknown, AHNAK-independent mechanism [102]. That being the case, how does TmeA-mediated inhibition AHNAK affect the host and benefit the pathogen? One possibility is that TmeA possesses an AHNAK-dependent, post-invasion function. However, the lack of an observed defect in replication or EB recovery in AHNAK-knockout MEFs would seem to contradict this hypothesis [102]. It is possible that any effect of AHNAK deficiency on pathogenesis was obscured by the choice of host; a murine, mesenchymal model for C. trachomatis infection likely has differing requirements for invasion relative to the polarized genital/ocular epithelium the pathogen infects in vivo. Unfortunately, the total knockdown of AHNAK has proven technically challenging in many cell lines [100,103]; continuing advances in CRISPR/Cas9 and related gene-editing techniques may thus be required to address this lingering question in a more physiologically relevant model.

The chlamydial toxin CT166 has also been proposed to indirectly mediate actin depolymerization, acting as an inhibitor of host actin-polymerizing factors. CT166 contains a DXD amino acid motif with homology to the Clostridium difficile toxin TcdB, a glucosylator of the Rho-family GTPases Rac1 and Cdc42 (both well-known regulators of actin polymerization) [104,105]. Glucosylation of Rac1/Cdc42 by TcdB is inhibitory and irreversible, occurring at a catalytic threonine residue essential for GTP binding [105]. The downstream effect of TcdB activity is a dramatic redistribution of filamentous actin, resulting in cell shrinking, the loss of stress fibers, and host cell death $[105,106]$.

CT166 is highly variable between $C$. trachomatis serovars: serovar D possesses a severely truncated CT166 that nevertheless retains the TcdB-homologous glucosylating domain, whereas serovar L2 lacks the gene entirely [104]. The inoculation of HeLa cells with C. trachomatis serovar D or C. muridarum (which possesses a full-length copy of CT166) at a high multiplicity of infection resulted in morphological defects and cytotoxicity, reminiscent of the effects of TcdB [104]. Importantly, cytotoxicity was not observed in a comparable infection using the CT166-deficient $C$. trachomatis serovar L2, suggesting that this phenomenon was CT166-specific [104]. It has since been shown that CT166 expressed in HeLa 
cells inactivates the Rac/Cdc42 relative Ras, and that this effect could be ablated via mutation of the DXD domain $[107,108]$.

CT166's role during invasion is somewhat unclear, given that the CT166-deficient $C$. trachomatis serovars can invade host cells in vitro with a comparable efficiency to those that possess the effector [104]. As with TmeA, this may be a product of the choice of host model; it remains to be seen whether CT166's glucosylating activity is equally dispensable in three-dimensional or organismal models of chlamydial infection. Given that the proposed function of CT166 runs counter to chlamydial invasion's established dependence on actin polymerization, it follows that the timing of CT166 delivery and activation is tightly regulated, in order to ensure that the toxin's activity is beneficial to the pathogen. Further study of CT166 may therefore inform the timing and kinetics of chlamydial effector delivery, as well as provide insight into the regulation of actin dynamics by the host.

\section{Life after Invasion: Chlamydia Modulates Actin for Inclusion Stability and Host Egress}

Given the robust and multifactorial nature of cytoskeletal restructuring during chlamydial invasion, it should not be surprising that the pathogen continues to manipulate the cytoskeleton once internalized by the host. Initial study of inclusion development has shown that Chlamydiae restructure the microtubule network to foster the development of their replicative niche. Another early observation of infections in vitro was that the treatment of infected cells with the microtubule polymerization inhibitor colchicine produces a marked increase in inclusion size [109]. Furthermore, rapid and inclusion-proximate microtubule assembly has been observed after washout of the microtubule-disrupting agent nocodazole [110,111]. It has been shown that Chlamydia-directed microtubule restructuring traffics the nascent $C$. trachomatis inclusion to the microtubule-organizing center (MTOC) - an outcome that is presumed to enable the chlamydial scavenging of nutrients from the host [111,112]. Indeed, the inclusion demonstrably interacts with a variety of nutrient-rich, MTOC-associated organelles, including the ER and multivesicular bodies (MVBs) [113-117]; pharmacological disruption of inclusion-ER/MVB association impairs chlamydial growth [113,115], consistent with a model of the chlamydial theft of nutrients from these organelles.

The role of actin in post-invasion chlamydial pathogenesis is more poorly characterized. In 1989, Campbell et al. discovered that mature inclusions are surrounded by a cage of actin and intermediate filaments [112], but it was only in the past decade that a mechanistic understanding of this structure's assembly and importance became clear. Additionally, recent study has shown that actin and actin-related structures play a role in pathogen egress, by facilitating the extrusion of intact chlamydial inclusions from the host.

\subsection{Actin-Mediated Reinforcement of the Inclusion}

As noted previously, early live-cell imaging experiments established the rapid recruitment of actin at the site of chlamydial invasion of the host [40]. Critically, the actin-rich structures surrounding invasion sites are transient, meaning that the actin-rich cage observed surrounding nascent inclusions is a distinct structure assembled later, likely with a separate function $[112,118,119]$. It has since been demonstrated that actin affords considerable stability to the inclusion: strikingly, treatment with $1 \%$ Triton X-100 does not significantly alter the morphology of the inclusion, despite the near-total solubilization of its membrane [118]. This apparent resistance to nonionic detergents was subsequently shown to depend on an F-actin ring surrounding the inclusion-actin disruption via latrunculin-A/B compromised the inclusion membrane integrity, leading to the detection of bacterial lipopolysaccharide (LPS) and antibody-labeled Chlamydia in the cytosol of infected cells [118]. Importantly, microtubule disruption with nocodazole did not produce similar changes in inclusion morphology. Taken together, these results imply a specific role for actin in structurally reinforcing the maturing inclusion [118].

The mechanism of actin recruitment to the inclusion remains somewhat unclear. Actin-rich structures in the host are largely indistinguishable from uninfected cells, in stark contrast to the pathogen's extensive remodeling of the microtubule network [110,112]. Furthermore, F-actin rings 
associated with maturing inclusions (30 hpi) are unaffected by the pharmacological disruption of stress fibers and cortical actin, including the inhibition of Rac1, Cdc42, ROCK, and myosin II [118]. Intriguingly, the inhibition of RhoA (either via siRNA knockdown or treatment with the Clostridium botulinum toxin C3-transferase) reduced the incidence of F-actin rings, and ablated the inclusion resistance to TX-100 [118]. Collectively, these results imply that the cage's actin component is assembled independently of host actin-rich structures.

More recent study of actin recruitment to the inclusion has complicated the model of cage assembly. Live-cell imaging of actin recruitment to mature inclusions (44 and $68 \mathrm{hpi}$ ) demonstrates sensitivity to formin inhibition (but not Arp2/3) [119], suggesting that cage formation may indeed depend upon the de novo, unbranched polymerization of actin at inclusions. However, actin recruitment at these time points occurred independently of RhoA and was sensitive to myosin II inhibition-seemingly in direct contradiction to ring assembly dynamics at earlier stages of infection [118,119]. How might data from these two stages of infection be reconciled? One explanation is that initial assembly and subsequent maintenance of the cage's actin component occurs via two distinct mechanisms-the former requiring RhoA, and the latter requiring formins and myosin II. A more longitudinal study of chlamydial actin recruitment is required to test this hypothesis, and may reveal how the mechanism of cage assembly changes with maturation of the inclusion.

Intermediate filaments have also been shown to contribute to the stability and function of the inclusion cage. While the infection of vimentin-knockout MEFs (a cell line also deficient in cytokeratins) produced F-actin rings comparable to the infection of wild-type cells, these rings lacked the highly compact and ordered morphology of their wild-type counterparts [118]. Inclusions in vimentin-knockout cells also lacked the previously observed resistance to TX-100. Taken together, these results suggest that the recruitment or assembly of F-actin rings surrounding the inclusion provides a scaffold for further inclusion reinforcement by intermediate filaments [118]. The chlamydial protease CPAF has been shown to cleave vimentin (as well as cytokeratin-8/18) within the protein's head domain, partially inhibiting its ability to form filamentous structures $[118,120,121]$. It is postulated that this interaction permits highly dynamic maintenance of the actin/filament cage, allowing the structure to accommodate an ever-expanding inclusion.

Collectively, these findings suggest that Chlamydiae dynamically reinforce the developing inclusion with F-actin and intermediate filaments (Figure 4). While the precise mechanism of F-actin synthesis and recruitment to the inclusion is somewhat unclear, the interconnected nature of the cytoskeleton would suggest that pathogen-directed actin restructuring may affect other cytoskeletal components, like the microtubule network. Given the established importance of the MTOC and vesicular trafficking to chlamydial growth (reviewed in detail by Nogueira et al. [122]), disruption of the microtubule network by any means has significant implications for the pathogen. Therefore, further study of the actin cage seems warranted, in order to evaluate a possible role for this structure in the chlamydial modulation of microtubule dynamics. 


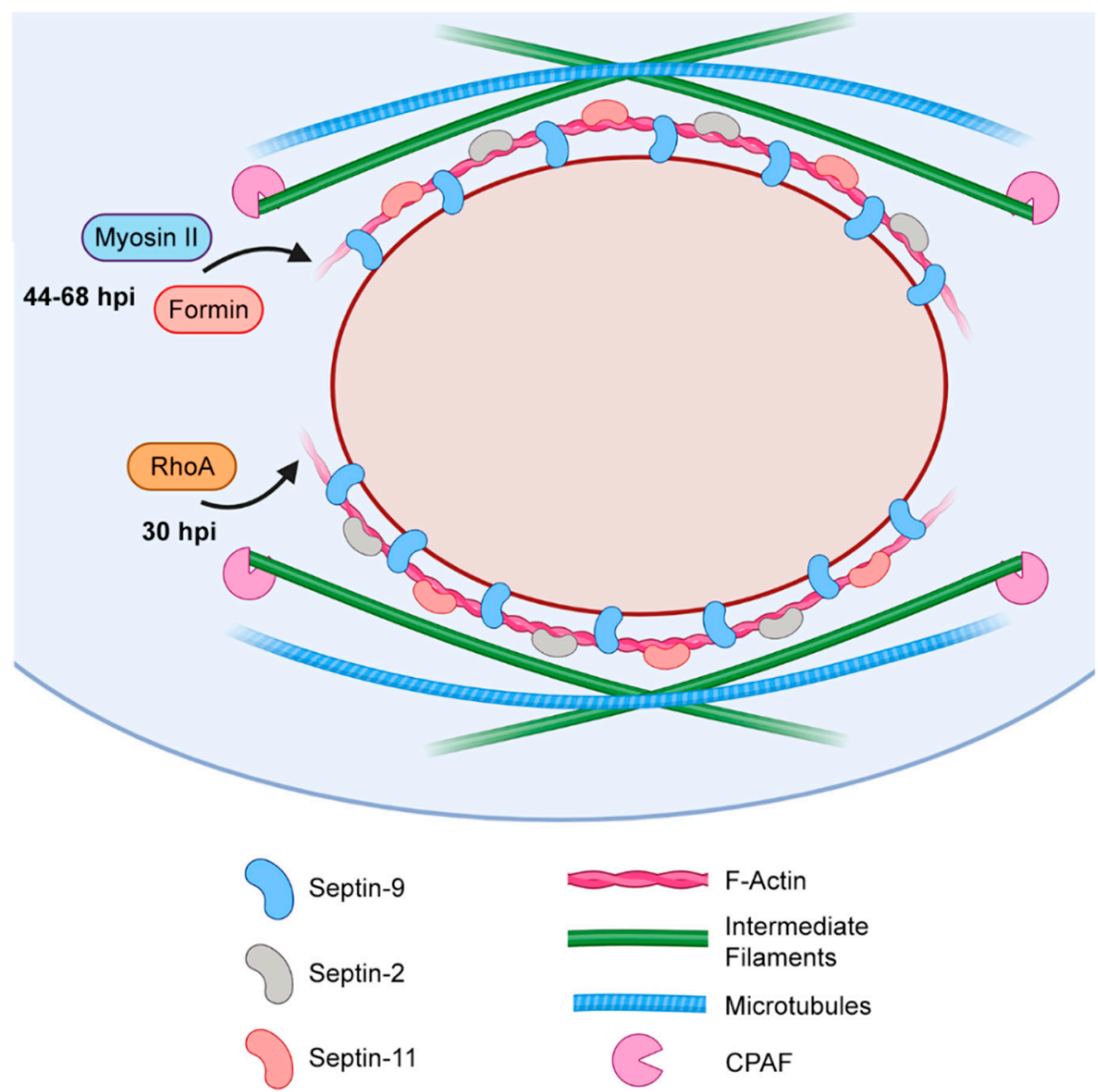

Figure 4. Diagram of the filamentous cage surrounding the maturing chlamydial inclusion.

\subsection{The Role of Actin in Chlamydial Extrusion}

Like other intracellular pathogens, Chlamydiae can exit the host via the induction of host cell lysis. However, another, less destructive, pathway exists as well. Early indication of an alternative mechanism of egress came in the observation of "scarred" host cells that-while intact-lacked a substantial portion of their plasma membranes [123]. Hybiske and Stephens proved the existence of non-lytic egress by taking advantage of the tendency of the chlamydial inclusion to exclude host cytosolic proteins [61]. Upon infecting GFP-expressing HeLa cells with C. trachomatis, they determined that while half of the observed inclusions became GFP-permeable during host cell lysis, the remaining half fused with the plasma membrane, excluding GFP throughout egress from the host, suggesting that an exocytotic event had occurred [61]. The incidence of this event (termed extrusion) was sensitive to disruption of the actin cytoskeleton by latrunculin B; intriguingly, the same did not hold true for nocodazole treatment, indicating that extrusion occurs independent of the microtubule network and conventional vesicular trafficking [61]. Further inhibitor treatments revealed a dependence on the nucleation promoting factor N-WASP, Rho-family GTPases, and myosin II. Taken together, these data imply an extrusion mechanism reliant on F-actin polymerization and bundling [61].

In 2013, Lutter et al. observed the recruitment of a complex of myosin-related host proteins to the inclusion surface, including myosin IIa; myosin Ilb; and the phosphorylated, active forms of myosin light chain 2 (MLC2) and myosin light chain kinase (MLCK) [124,125]. The depletion of these myosin-activating factors via siRNA knockdown reduced the incidence of extrusion events, suggesting that Chlamydia-directed activation of myosin II promotes non-lytic egress of the pathogen [124]. Accordingly, the inclusion surface protein CT228 has been shown to directly interact with MYPT1, a negative regulator of myosin II activity. MYPT1 acts as a regulatory subunit of the phosphatase PP2-upon binding, MYPT1 alters the phosphatase's binding specificity, resulting in the PP2-mediated 
dephosphorylation (and, thereby, inactivation) of MLC2 [126]. The binding of MYPT1 to PP2 can be inhibited by the former's phosphorylation-given that CT228 preferentially recruits phosphorylated MYPT1 to the inclusion surface, it was initially proposed that CT228 might facilitate extrusion via MYPT1 inhibition [124].

However, the recent finding that the TargeTron-mediated knockout of CT228 increases the extrusion incidence (consistent with the siRNA-mediated knockdown of MYPT1) indicates an alternative, extrusion-inhibitory role for CT228 [127]. Combined with the earlier observation of the robust dephosphorylation of MYPT1 late in infection (42 hpi), this result suggests that CT228-mediated MYPT1 recruitment may result in MYPT1 activation instead [127], perhaps serving as a mechanism to regulate myosin II activity at the inclusion (and thereby regulating extrusion-mediated egress of the pathogen). Extrusion is further regulated by the interaction of the chlamydial inclusion membrane protein MrcA with IPTR3, an inositol 1,4,5-triphosphate receptor that acts as a $\mathrm{Ca}^{2+}$ channel [128]. Accordingly, the regulatory action of this complex further required the host cell Ca2+ sensor STIM1 [128]. It is important to note that premature host egress (i.e. prior to the differentiation of Chlamydia into infectious EBs) is a disastrous outcome for the pathogen that precludes subsequent infection of the surrounding tissue. The temporal regulation of MYPT1 activity via the expression of CT228 may therefore constitute a means by which Chlamydiae inhibit extrusion until differentiation is complete, thereby ensuring the release of invasion-competent organisms.

Further study has put forward a connection between the inclusion's actin cage and extrusion, specifically involving the septin family of GTP-binding proteins [129]. The function of septins is primarily structural — upon binding to GTP, septins oligomerize to form filamentous structures that associate with F-actin and other cytoskeletal components [130]. Accordingly, septin-2, 9, and 11 were recently observed to colocalize with the actin-rich structures surrounding the maturing inclusion [129]. Septin-9 knockdown both ablated actin recruitment to the inclusion and resulted in a 2 to 3 -fold reduction of extrusion events [129], suggesting that these processes are functionally interrelated. This exciting result prompts several questions: does the structural content of the inclusion cage bias chlamydial egress via one pathway over another? How might the various structural components of the cage contribute to the activity of CT228 and myosin II? Further research in this area may indicate how actin, intermediate filaments, and septins contribute to vesicular trafficking and exocytosis, as well as provide insight into their specific role in chlamydial egress.

\section{Conclusions and Summary}

While mechanistic study of the actin modulation by Chlamydiae is both robust and ongoing, it is important to acknowledge that actin remodeling does not occur in a vacuum, and that the effect of Chlamydia-restructured actin on the host cell has been largely unassessed. The actin cytoskeleton is much more than a structural network for the host—in addition to driving endocytosis and cellular motility, mounting evidence implicates actin dynamics in transcriptional regulation.

The tensile force transmitted across actin filaments has been demonstrated to induce changes in gene expression, via the activity of actin- and/or tension-responsive signaling pathways. For example, the serum response factor (SRF) is demonstrably activated by regulators of actin dynamics, such as the cofilin-inhibiting LIM kinase-1 [131]. The application of tensile force to cardiac fibroblasts in vitro has shown the tension-dependent expression of $\alpha$-smooth muscle actin, an SRF regulatory target [132]. Dysregulation of SRF activity has been associated with induction of the epithelial-to-mesenchymal transition (EMT) - a process through which epithelial cells transdifferentiate into scar-forming fibroblasts $[133,134]$. Intriguingly, Chlamydia infection has recently been shown to induce EMT, which likely promotes the scar-forming pathology observed in chronic C. trachomatis infections [79,135-137]. Could chlamydial restructuring of actin contribute to this effect? Further characterization of actin-regulated gene expression in Chlamydia-infected cells appears warranted.

Force transduction across the actin cytoskeleton also has demonstrable effects on the nuclear architecture. The inner nuclear membrane (INM) is reinforced by a network of intermediate filaments 
and associated proteins-including lamin- $\mathrm{A} / \mathrm{C}$ and emerin — that are structurally integrated with the cytoskeleton via the LINC (linker of nucleoskeleton and cytoskeleton) complex [138]. Tension-mediated phosphorylation of emerin is associated with redistribution of the LINC complex and nuclear actin, which in turn are respectively associated with chromatin remodeling and myocardin-related transcription factor (MRTF) activity [139-142]. Given the multifaceted way in which Chlamydiae restructure actin and modulate the activity of myosin II-a contractile, actin-crosslinking protein-it is plausible that infection has the secondary effect of modulating tension- and actin-responsive gene expression, and that characterization of this effect may provide insight into chlamydial pathogenesis.

The polarized epithelial mucosa that Chlamydiae typically infect often react to bacterial insult via the concerted exfoliation and apoptosis of infected cells-a process that requires the degradation of focal adhesions and related cell-ECM adherent structures, as well as extensive remodeling of the actin cytoskeleton [143]. Exfoliation and apoptosis of the host cell is clearly an unfavorable outcome for any intracellular pathogen. Accordingly, there is evidence indicating that other intracellular bacteria inhibit this host response to infection. The Shigella flexneri effector OspE has been shown to reinforce sites of cell-ECM contact through an interaction with integrin-linked kinase (ILK), which results in an increased incidence of integrin- $\beta 1$ on the host cell surface and the consequent assembly of focal adhesions [144]. A secondary effect of the OspE modulation of ILK is the stabilization of focal adhesions, via the inhibition of focal adhesion kinase (FAK). Given that the chlamydial effector TarP is known to recruit FAK (albeit in the context of invasion) [70], it is tempting to speculate that Chlamydia might inhibit exfoliation in a similar fashion. Ultimately, further characterization of host cell adherence and exfoliation during chlamydial infection is necessary to address this hypothesis.

In summary, ongoing study of actin modulation by Chlamydiae has revealed the multifaceted way in which these pathogens restructure the host actin cytoskeleton. During the two-stage attachment of chlamydial EBs to the host cell surface, the pathogen engages with a variety of host surface proteins-including galectin-1, FGFR, and PDGFR $\beta$ - that in turn facilitate the recruitment of signaling factors promoting actin polymerization at the attachment site [33,52-54,63]. The subsequent delivery of chlamydial effectors by the pathogen's type III secretion system then induces actin-dependent invasion of the host cell. The chlamydial effector TarP contributes to this effect in multiple ways: via the recruitment of F-actin and Arp2/3 actin-polymerizing complexes, via direct nucleation of actin polymerization, and by providing a scaffold for actin-modulatory signaling $[69-71,84,85]$. While the mechanism by which actin regulation at the invasion site returns to a steady state remains somewhat unclear, the chlamydial effectors TmeA and CT166 have been demonstrated to inhibit F-actin bundling and polymerization, respectively, and may contribute to this process $[98,99,102,104,107,108]$. Once invasion is complete, actin is recruited in either an RhoA- or ROCK-dependent fashion to the maturing inclusion alongside intermediate filaments and septins, providing dynamic structural reinforcement to Chlamydia's replicative niche $[118,119]$. Finally, non-lytic chlamydial egress from the host depends on actin polymerization, as well as the modulation of myosin II by the inclusion membrane protein CT228 [61,124,127]. While the mechanistic underpinnings of actin restructuring by Chlamydiae are coming into focus, the effects of this restructuring on the host are relatively uncharacterized, presenting intriguing opportunities for future study.

Author Contributions: Conceptualization, L.C. and R.A.C.; writing-original draft preparation, L.C.; writing-review and editing, R.A.C.; visualization, L.C.; supervision, R.A.C.; project administration, R.A.C.; funding acquisition, R.A.C. All authors have read and agreed to the published version of the manuscript.

Funding: This research was funded by the National Institutes of Health, grant number AI065545.

Acknowledgments: The authors acknowledge Amanda Brinkworth for a critical review of the manuscript. Figure 1; Figure 4 were created with BioRender.

Conflicts of Interest: The authors declare no conflicts of interest. 


\section{Abbreviations}

\begin{tabular}{|c|c|}
\hline G-actin & Globular actin \\
\hline F-actin & Filamentous actin \\
\hline Arp2/3 & Actin-related protein $2 / 3$ \\
\hline $\mathrm{NPF}$ & Nucleation promotion factor \\
\hline N-WASP & Neuronal Wiskott-Aldrich Syndrome protein \\
\hline WAVE & WASP-family verprolin-homologous family protein \\
\hline WASH & Wiskott-Aldrich syndrome and SCAR homolog \\
\hline GTP & Guanosine-5'-triphosphate \\
\hline EPEC & Enteropathogenic Escherichia coli \\
\hline EHEC & Enterohemorrhagic Escherichia coli \\
\hline T3SS & Type III Secretion System \\
\hline EB & Elementary body \\
\hline GAG & Glycosaminoglycan \\
\hline MOMP & Major outer membrane protein \\
\hline FGF & Fibroblast growth factor \\
\hline FGFR & Fibroblast growth factor receptor \\
\hline PDGFR $\beta$ & Platelet-derived growth factor receptor beta \\
\hline $\mathrm{Abl}$ & Abelson-family kinase \\
\hline TarP & Translocated actin recruitment protein \\
\hline EGTA & Ethylene glycol-bis( $\beta$-aminoethyl ether)- $\mathrm{N}, \mathrm{N}, \mathrm{N}^{\prime}, \mathrm{N}^{\prime}$-tetraacetic acid \\
\hline PRD & Proline-rich domain \\
\hline $\mathrm{ABD}$ & Actin binding domain \\
\hline FAK & Focal adhesion kinase \\
\hline LD & Leucine-aspartatic acid repeat domain \\
\hline VBD & Vinculin binding domain \\
\hline ECM & Extracellular matrix \\
\hline EMT & Epithelial-mesenchymal transition \\
\hline hpi & Hours post-infection \\
\hline MEF & Mouse embryonic fibroblast \\
\hline MTOC & Microtubule organizing center \\
\hline ER & Endoplasmic reticulum \\
\hline MVB & Multivesicular body \\
\hline ROCK & Rho-associated protein kinase \\
\hline CPAF & Chlamydial protease/proteasome-like activity factor \\
\hline MLC2 & Myosin light chain 2 \\
\hline MLCK & Myosin light chain kinase \\
\hline MYPT1 & Myosin phosphatase target subunit 1 \\
\hline PP2 & Protein phosphatase 2 \\
\hline IPTR3 & Inositol-1,4,5-triphosphate receptor, type 3 \\
\hline SRF & Serum response factor \\
\hline MRTF & Myocardin-related transcription factor \\
\hline INM & Inner nuclear membrane \\
\hline LINC & Linker of nucleoskeleton and cytoskeleton \\
\hline ILK & Integrin-linked kinase \\
\hline
\end{tabular}

\section{References}

1. Goley, E.D.; Welch, M.D. The ARP2/3 complex: An actin nucleator comes of age. Nat. Rev. Mol. Cell Biol. 2006, 7, 713-726. [CrossRef] [PubMed]

2. Pollard, T.D. Regulation of actin filament assembly by Arp2/3 complex and formins. Annu. Rev. Biophys. Biomol. Struct. 2007, 36, 451-477. [CrossRef] [PubMed]

3. Rotty, J.D.; Wu, C.; Bear, J.E. New insights into the regulation and cellular functions of the ARP2/3 complex. Nat. Rev. Mol. Cell Biol. 2013, 14, 7-12. [CrossRef] [PubMed] 
4. Machesky, L.M.; Mullins, R.D.; Higgs, H.N.; Kaiser, D.A.; Blanchoin, L.; May, R.C.; Hall, M.E.; Pollard, T.D. Scar, a WASp-related protein, activates nucleation of actin filaments by the Arp2/3 complex. Proc. Natl. Acad. Sci. USA 1999, 96, 3739-3744. [CrossRef] [PubMed]

5. Linardopoulou, E.V.; Parghi, S.S.; Friedman, C.; Osborn, G.E.; Parkhurst, S.M.; Trask, B.J. Human Subtelomeric WASH Genes Encode a New Subclass of the WASP Family. PLoS Genet. 2007, 3, e237. [CrossRef] [PubMed]

6. Hodge, R.G.; Ridley, A.J. Regulating Rho GTPases and their regulators. Nat. Rev. Mol. Cell Biol. 2016, 17, 496-510. [CrossRef] [PubMed]

7. Popoff, M.R. Bacterial factors exploit eukaryotic Rho GTPase signaling cascades to promote invasion and proliferation within their host. Small GTPases 2014, 5, e983863. [CrossRef]

8. Zhou, D.; Chen, L.M.; Hernandez, L.; Shears, S.B.; Galán, J.E. A Salmonella inositol polyphosphatase acts in conjunction with other bacterial effectors to promote host cell actin cytoskeleton rearrangements and bacterial internalization. Mol. Microbiol. 2001, 39, 248-259. [CrossRef]

9. Stender, S.; Friebel, A.; Linder, S.; Rohde, M.; Mirold, S.; Hardt, W.-D. Identification of SopE2 from Salmonella typhimurium, a conserved guanine nucleotide exchange factor for Cdc42 of the host cell. Mol. Microbiol. 2000, 36, 1206-1221. [CrossRef]

10. Hardt, W.D.; Chen, L.M.; Schuebel, K.E.; Bustelo, X.R.; Galán, J.E.S. typhimurium encodes an activator of Rho GTPases that induces membrane ruffling and nuclear responses in host cells. Cell 1998, 93, 815-826. [CrossRef]

11. Friebel, A.; Ilchmann, H.; Aepfelbacher, M.; Ehrbar, K.; Machleidt, W.; Hardt, W.-D. SopE and SopE2 from Salmonella typhimurium Activate Different Sets of RhoGTPases of the Host Cell. J. Biol. Chem. 2001, 276, 34035-34040. [CrossRef] [PubMed]

12. Hardt, W.D.; Urlaub, H.; Galán, J.E. A substrate of the centisome 63 type III protein secretion system of Salmonella typhimurium is encoded by a cryptic bacteriophage. Proc. Natl. Acad. Sci. USA 1998, 95, 2574-2579. [CrossRef] [PubMed]

13. Garcia-del Portillo, F.; Finlay, B.B. Salmonella invasion of nonphagocytic cells induces formation of macropinosomes in the host cell. Infect. Immun. 1994, 62, 4641-4645. [PubMed]

14. Humphreys, D.; Davidson, A.; Hume, P.J.; Koronakis, V. Salmonella virulence effector SopE and Host GEF ARNO cooperate to recruit and activate WAVE to trigger bacterial invasion. Cell Host Microbe 2012, 11, 129-139. [CrossRef]

15. Boujemaa-Paterski, R.; Gouin, E.; Hansen, G.; Samarin, S.; Le Clainche, C.; Didry, D.; Dehoux, P.; Cossart, P.; Kocks, C.; Carlier, M.F.; et al. Listeria protein ActA mimics WASp family proteins: It activates filament barbed end branching by Arp2/3 complex. Biochemistry 2001, 40, 11390-11404. [CrossRef]

16. Welch, M.D.; Rosenblatt, J.; Skoble, J.; Portnoy, D.A.; Mitchison, T.J. Interaction of human Arp2/3 complex and the Listeria monocytogenes ActA protein in actin filament nucleation. Science 1998, 281, 105-108. [CrossRef]

17. Skoble, J.; Portnoy, D.A.; Welch, M.D. Three regions within ActA promote Arp2/3 complex-mediated actin nucleation and Listeria monocytogenes motility. J. Cell Biol. 2000, 150, 527-538. [CrossRef]

18. Ireton, K. Molecular mechanisms of cell-cell spread of intracellular bacterial pathogens. Open Biol. 2013, 3, 130079. [CrossRef]

19. Welch, M.D.; Way, M. Arp2/3-mediated actin-based motility: A tail of pathogen abuse. Cell Host Microbe 2013, 14, 242-255. [CrossRef]

20. Lamason, R.L.; Welch, M.D. Actin-based motility and cell-to-cell spread of bacterial pathogens. Curr. Opin. Microbiol. 2017, 35, 48-57. [CrossRef]

21. Kenny, B.; DeVinney, R.; Stein, M.; Reinscheid, D.J.; Frey, E.A.; Finlay, B.B. Enteropathogenic E. coli (EPEC) Transfers Its Receptor for Intimate Adherence into Mammalian Cells. Cell 1997, 91, 511-520. [CrossRef]

22. Deibel, C.; Krämer, S.; Chakraborty, T.; Ebel, F. EspE, a novel secreted protein of attaching and effacing bacteria, is directly translocated into infected host cells, where it appears as a tyrosine-phosphorylated 90 kDa protein. Mol. Microbiol. 1998, 28, 463-474. [CrossRef] [PubMed]

23. Warawa, J.; Kenny, B. Phosphoserine modification of the enteropathogenic Escherichia coli Tir molecule is required to trigger conformational changes in Tir and efficient pedestal elongation. Mol. Microbiol. 2001, 42, 1269-1280. [CrossRef] [PubMed]

24. Campellone, K.G.; Rankin, S.; Pawson, T.; Kirschner, M.W.; Tipper, D.J.; Leong, J.M. Clustering of Nck by a 12-residue Tir phosphopeptide is sufficient to trigger localized actin assembly. J. Cell Biol. 2004, 164, 407-416. [CrossRef] 
25. Gruenheid, S.; DeVinney, R.; Bladt, F.; Goosney, D.; Gelkop, S.; Gish, G.D.; Pawson, T.; Finlay, B.B. Enteropathogenic E. coli Tir binds Nck to initiate actin pedestal formation in host cells. Nat. Cell Biol. 2001, 3, 856-859. [CrossRef]

26. Frankel, G.; Phillips, A.D. Attaching effacing Escherichia coli and paradigms of Tir-triggered actin polymerization: Getting off the pedestal. Cell. Microbiol. 2008, 10, 549-556. [CrossRef]

27. Garmendia, J.; Frankel, G.; Crepin, V.F. Enteropathogenic and Enterohemorrhagic Escherichia coli Infections: Translocation, Translocation, Translocation. Infect. Immun. 2005, 73, 2573-2585. [CrossRef]

28. Elwell, C.; Mirrashidi, K.; Engel, J. Chlamydia cell biology and pathogenesis. Nat. Rev. Microbiol. 2016, 14, 385-400. [CrossRef]

29. Malhotra, M.; Sood, S.; Mukherjee, A.; Muralidhar, S.; Bala, M. Genital Chlamydia trachomatis: An update. Indian J. Med. Res. 2013, 138, 303-316.

30. Braun, C.; Alcázar-Román, A.R.; Laska, A.; Mölleken, K.; Fleig, U.; Hegemann, J.H. CPn0572, the C. pneumoniae ortholog of TarP, reorganizes the actin cytoskeleton via a newly identified F-actin binding domain and recruitment of vinculin. PLoS ONE 2019, 14, e0210403. [CrossRef]

31. Zrieq, R.; Braun, C.; Hegemann, J.H. The Chlamydia pneumoniae Tarp Ortholog CPn0572 Stabilizes Host F-Actin by Displacement of Cofilin. Front. Cell. Infect. Microbiol. 2017, 7, 511. [CrossRef] [PubMed]

32. Jiwani, S.; Alvarado, S.; Ohr, R.J.; Romero, A.; Nguyen, B.; Jewett, T.J. Chlamydia trachomatis Tarp Harbors Distinct G and F Actin Binding Domains That Bundle Actin Filaments. J. Bacteriol. 2013, 195, 708-716. [CrossRef] [PubMed]

33. Elwell, C.A.; Ceesay, A.; Kim, J.H.; Kalman, D.; Engel, J.N. RNA Interference Screen Identifies Abl Kinase and PDGFR Signaling in Chlamydia trachomatis Entry. PLoS Pathog. 2008, 4, e1000021. [CrossRef] [PubMed]

34. Clifton, D.R.; Dooley, C.A.; Grieshaber, S.S.; Carabeo, R.A.; Fields, K.A.; Hackstadt, T. Tyrosine Phosphorylation of the Chlamydial Effector Protein Tarp Is Species Specific and Not Required for Recruitment of Actin. Infect. Immun. 2005, 73, 3860-3868. [CrossRef] [PubMed]

35. Carabeo, R. Bacterial subversion of host actin dynamics at the plasma membrane. Cell. Microbiol. 2011, 13, 1460-1469. [CrossRef] [PubMed]

36. Carabeo, R.A.; Grieshaber, S.S.; Fischer, E.; Hackstadt, T. Chlamydia trachomatis Induces Remodeling of the Actin Cytoskeleton during Attachment and Entry into HeLa Cells. Infect. Immun. 2002, 70, 3793-3803. [CrossRef]

37. Ford, C.; Nans, A.; Boucrot, E.; Hayward, R.D. Chlamydia exploits filopodial capture and a macropinocytosislike pathway for host cell entry. PLoS Pathog. 2018, 14, e1007051. [CrossRef]

38. Kuo, C.C.; Grayston, T. Interaction of Chlamydia trachomatis organisms and HeLa 229 cells. Infect. Immun. 1976, 13, 1103-1109.

39. Byrne, G.I. Kinetics of phagocytosis of Chlamydia psittaci by mouse fibroblasts (L cells): Separation of the attachment and ingestion stages. Infect. Immun. 1978, 19, 607-612.

40. Carabeo, R.A.; Hackstadt, T. Isolation and Characterization of a Mutant Chinese Hamster Ovary Cell Line That Is Resistant to Chlamydia trachomatis Infection at a Novel Step in the Attachment Process. Infect. Immun. 2001, 69, 5899-5904. [CrossRef]

41. Moulder, J.W. Interaction of chlamydiae and host cells in vitro. Microbiol. Mol. Biol. Rev. 1991, 55, 143-190.

42. Tiwari, V.; Maus, E.; Sigar, I.M.; Ramsey, K.H.; Shukla, D. Role of heparan sulfate in sexually transmitted infections. Glycobiology 2012, 22, 1402-1412. [CrossRef] [PubMed]

43. Taraktchoglou, M.; Pacey, A.A.; Turnbull, J.E.; Eley, A. Infectivity of Chlamydia trachomatis serovar LGV but not $\mathrm{E}$ is dependent on host cell heparan sulfate. Infect. Immun. 2001, 69, 968-976. [CrossRef] [PubMed]

44. Sugahara, K.; Kitagawa, H. Heparin and heparan sulfate biosynthesis. IUBMB Life 2002, 54, 163-175. [CrossRef] [PubMed]

45. Rasmussen-Lathrop, S.J.; Koshiyama, K.; Phillips, N.; Stephens, R.S. Chlamydia-dependent biosynthesis of a heparan sulphate-like compound in eukaryotic cells. Cell. Microbiol. 2000, 2, 137-144. [CrossRef]

46. Stephens, R.S. Molecular mimicry and Chlamydia trachomatis infection of eukaryotic cells. Trends Microbiol. 1994, 2, 99-101. [CrossRef]

47. Zhang, J.P.; Stephens, R.S. Mechanism of C. trachomatis attachment to eukaryotic host cells. Cell 1992, 69, 861-869. [CrossRef]

48. Fadel, S.; Eley, A. Chlamydia trachomatis OmcB protein is a surface-exposed glycosaminoglycan-dependent adhesin. J. Med. Microbiol. 2007, 56, 15-22. [CrossRef] 
49. Moelleken, K.; Hegemann, J.H. The Chlamydia outer membrane protein OmcB is required for adhesion and exhibits biovar-specific differences in glycosaminoglycan binding. Mol. Microbiol. 2008, 67, 403-419. [CrossRef]

50. Fechtner, T.; Stallmann, S.; Moelleken, K.; Meyer, K.L.; Hegemann, J.H. Characterization of the interaction between the chlamydial adhesin OmcB and the human host cell. J. Bacteriol. 2013, 195, 5323-5333. [CrossRef]

51. Su, H.; Raymond, L.; Rockey, D.D.; Fischer, E.; Hackstadt, T.; Caldwell, H.D. A recombinant Chlamydia trachomatis major outer membrane protein binds to heparan sulfate receptors on epithelial cells. Proc. Natl. Acad. Sci. USA 1996, 93, 11143-11148. [CrossRef] [PubMed]

52. Campbell, L.A.; Lee, A.; Kuo, C. Cleavage of the N-linked oligosaccharide from the surfaces of Chlamydia species affects infectivity in the mouse model of lung infection. Infect. Immun. 2006, 74, 3027-3029. [CrossRef] [PubMed]

53. Swanson, A.F.; Kuo, C.C. Evidence that the major outer membrane protein of Chlamydia trachomatis is glycosylated. Infect. Immun. 1991, 59, 2120-2125. [PubMed]

54. Lujan, A.L.; Croci, D.O.; Gambarte Tudela, J.A.; Losinno, A.D.; Cagnoni, A.J.; Mariño, K.V.; Damiani, M.T.; Rabinovich, G.A. Glycosylation-dependent galectin-receptor interactions promote Chlamydia trachomatis infection. Proc. Natl. Acad. Sci. USA 2018, 115, E6000-E6009. [CrossRef]

55. Quintá, H.R.; Wilson, C.; Blidner, A.G.; González-Billault, C.; Pasquini, L.A.; Rabinovich, G.A.; Pasquini, J.M. Ligand-mediated Galectin-1 endocytosis prevents intraneural $\mathrm{H}_{2} \mathrm{O}_{2}$ production promoting $\mathrm{F}$-actin dynamics reactivation and axonal re-growth. Exp. Neurol. 2016, 283, 165-178. [CrossRef]

56. Boleti, H.; Benmerah, A.; Ojcius, D.M.; Cerf-Bensussan, N.; Dautry-Varsat, A. Chlamydia infection of epithelial cells expressing dynamin and Eps15 mutants: Clathrin-independent entry into cells and dynamin-dependent productive growth. J. Cell Sci. 1999, 112, 1487-1496.

57. Benmerah, A.; Gagnon, J.; Bègue, B.; Mégarbané, B.; Dautry-Varsat, A.; Cerf-Bensussan, N. The tyrosine kinase substrate eps15 is constitutively associated with the plasma membrane adaptor AP-2. J. Cell Biol. 1995, 131, 1831-1838. [CrossRef]

58. Tebar, F.; Sorkina, T.; Sorkin, A.; Ericsson, M.; Kirchhausen, T. Eps15 is a component of clathrin-coated pits and vesicles and is located at the rim of coated pits. J. Biol. Chem. 1996, 271, 28727-28730. [CrossRef]

59. Benmerah, A.; Lamaze, C.; Bègue, B.; Schmid, S.L.; Dautry-Varsat, A.; Cerf-Bensussan, N. AP-2/Eps15 interaction is required for receptor-mediated endocytosis. J. Cell Biol. 1998, 140, 1055-1062. [CrossRef]

60. Benmerah, A.; Bayrou, M.; Cerf-Bensussan, N.; Dautry-Varsat, A. Inhibition of clathrin-coated pit assembly by an Eps15 mutant. J. Cell Sci. 1999, 112, 1303-1311.

61. Hybiske, K.; Stephens, R.S. Mechanisms of host cell exit by the intracellular bacterium Chlamydia. Proc. Natl. Acad. Sci. USA 2007, 104, 11430-11435. [CrossRef] [PubMed]

62. Romero, M.D.; Mölleken, K.; Hegemann, J.H.; Carabeo, R.A. Chlamydia Adhesion and Invasion. In Chlamydia Biology: From Genome to Disease; Caister Academic Press: Poole, UK, 2020; ISBN 978-1-912530-28-1.

63. Kim, J.H.; Jiang, S.; Elwell, C.A.; Engel, J.N. Chlamydia trachomatis co-opts the FGF2 signaling pathway to enhance infection. PLoS Pathog. 2011, 7, e1002285. [CrossRef] [PubMed]

64. Gotoh, N. Regulation of growth factor signaling by FRS2 family docking/scaffold adaptor proteins. Cancer Sci. 2008, 99, 1319-1325. [CrossRef]

65. Birkelund, S.; Johnsen, H.; Christiansen, G. Chlamydia trachomatis serovar L2 induces protein tyrosine phosphorylation during uptake by HeLa cells. Infect. Immun. 1994, 62, 4900-4908. [PubMed]

66. Fawaz, F.S.; van Ooij, C.H.; Homola, E.L.; Mutka, S.C.; Engel, J.N. Infection with Chlamydia trachomatis alters the tyrosine phosphorylation and/or localization of several host cell proteins including cortactin. Infect. Immun. 1997, 65, 5301-5308.

67. Clifton, D.R.; Fields, K.A.; Grieshaber, S.S.; Dooley, C.A.; Fischer, E.R.; Mead, D.J.; Carabeo, R.A.; Hackstadt, T. A chlamydial type III translocated protein is tyrosine-phosphorylated at the site of entry and associated with recruitment of actin. Proc. Natl. Acad. Sci. USA 2004, 101, 10166-10171. [CrossRef]

68. Lutter, E.I.; Bonner, C.; Holland, M.J.; Suchland, R.J.; Stamm, W.E.; Jewett, T.J.; McClarty, G.; Hackstadt, T. Phylogenetic Analysis of Chlamydia trachomatis Tarp and Correlation with Clinical Phenotype. Infect. Immun. 2010, 78, 3678-3688. [CrossRef]

69. Jewett, T.J.; Miller, N.J.; Dooley, C.A.; Hackstadt, T. The Conserved Tarp Actin Binding Domain Is Important for Chlamydial Invasion. PLoS Pathog. 2010, 6, e1000997. [CrossRef] 
70. Thwaites, T.; Nogueira, A.T.; Campeotto, I.; Silva, A.P.; Grieshaber, S.S.; Carabeo, R.A. The Chlamydia Effector TarP Mimics the Mammalian Leucine-Aspartic Acid Motif of Paxillin to Subvert the Focal Adhesion Kinase during Invasion. J. Biol. Chem. 2014, 289, 30426-30442. [CrossRef]

71. Thwaites, T.R.; Pedrosa, A.T.; Peacock, T.P.; Carabeo, R.A. Vinculin Interacts with the Chlamydia Effector TarP Via a Tripartite Vinculin Binding Domain to Mediate Actin Recruitment and Assembly at the Plasma Membrane. Front. Cell. Infect. Microbiol. 2015, 5, 88. [CrossRef]

72. Hynes, R.O. Integrins: Bidirectional, allosteric signaling machines. Cell 2002, 110, 673-687. [CrossRef]

73. Schaller, M.D.; Hildebrand, J.D.; Shannon, J.D.; Fox, J.W.; Vines, R.R.; Parsons, J.T. Autophosphorylation of the focal adhesion kinase, pp125FAK, directs SH2-dependent binding of pp60src. Mol. Cell. Biol. 1994, 14, 1680-1688. [CrossRef] [PubMed]

74. Parsons, J.T. Focal adhesion kinase: The first ten years. J. Cell Sci. 2003, 116, 1409-1416. [CrossRef] [PubMed]

75. Calalb, M.B.; Polte, T.R.; Hanks, S.K. Tyrosine phosphorylation of focal adhesion kinase at sites in the catalytic domain regulates kinase activity: A role for Src family kinases. Mol. Cell. Biol. 1995, 15, 954-963. [CrossRef]

76. Schlaepfer, D.D.; Hunter, T. Signal transduction from the extracellular matrix-a role for the focal adhesion protein-tyrosine kinase FAK. Cell Struct. Funct. 1996, 21, 445-450. [CrossRef]

77. Huveneers, S.; Danen, E.H.J. Adhesion signaling-crosstalk between integrins, Src and Rho. J. Cell Sci. 2009, 122, 1059-1069. [CrossRef]

78. Stallmann, S.; Hegemann, J.H. The Chlamydia trachomatis Ctad1 invasin exploits the human integrin $\beta 1$ receptor for host cell entry. Cell. Microbiol. 2016, 18, 761-775. [CrossRef]

79. Igietseme, J.U.; Omosun, Y.; Stuchlik, O.; Reed, M.S.; Partin, J.; He, Q.; Joseph, K.; Ellerson, D.; Bollweg, B.; George, Z.; et al. Role of Epithelial-Mesenchyme Transition in Chlamydia Pathogenesis. PLoS ONE 2015, 10, e0145198. [CrossRef]

80. Belland, R.J.; Nelson, D.E.; Virok, D.; Crane, D.D.; Hogan, D.; Sturdevant, D.; Beatty, W.L.; Caldwell, H.D. Transcriptome analysis of chlamydial growth during IFN- $\gamma$-mediated persistence and reactivation. Proc. Natl. Acad. Sci. USA 2003, 100, 15971-15976. [CrossRef]

81. Carlson, J.H.; Porcella, S.F.; McClarty, G.; Caldwell, H.D. Comparative Genomic Analysis of Chlamydia trachomatis Oculotropic and Genitotropic Strains. Infect. Immun. 2005, 73, 6407-6418. [CrossRef]

82. Thomson, N.R.; Holden, M.T.G.; Carder, C.; Lennard, N.; Lockey, S.J.; Marsh, P.; Skipp, P.; O'Connor, C.D.; Goodhead, I.; Norbertzcak, H.; et al. Chlamydia trachomatis: Genome sequence analysis of lymphogranuloma venereum isolates. Genome Res. 2008, 18, 161-171. [CrossRef] [PubMed]

83. Jewett, T.J.; Dooley, C.A.; Mead, D.J.; Hackstadt, T. Chlamydia trachomatis TarP is phosphorylated by src family tyrosine kinases. Biochem. Biophys. Res. Commun. 2008, 371, 339-344. [CrossRef] [PubMed]

84. Lane, B.J.; Mutchler, C.; Al Khodor, S.; Grieshaber, S.S.; Carabeo, R.A. Chlamydial Entry Involves TARP Binding of Guanine Nucleotide Exchange Factors. PLoS Pathog. 2008, 4, e1000014. [CrossRef] [PubMed]

85. Carabeo, R.A.; Dooley, C.A.; Grieshaber, S.S.; Hackstadt, T. Rac interacts with Abi-1 and WAVE2 to promote an Arp2/3-dependent actin recruitment during chlamydial invasion. Cell. Microbiol. 2007, 9, 2278-2288. [CrossRef] [PubMed]

86. Ghosh, S.; Park, J.; Thomas, M.; Cruz, E.; Cardona, O.; Kang, H.; Jewett, T. Biophysical characterization of actin bundles generated by the Chlamydia trachomatis Tarp effector. Biochem. Biophys. Res. Commun. 2018, 500, 423-428. [CrossRef] [PubMed]

87. McGhie, E.J.; Hayward, R.D.; Koronakis, V. Control of actin turnover by a salmonella invasion protein. Mol. Cell 2004, 13, 497-510. [CrossRef]

88. Bierne, H.; Gouin, E.; Roux, P.; Caroni, P.; Yin, H.L.; Cossart, P. A role for cofilin and LIM kinase in Listeria-induced phagocytosis. J. Cell Biol. 2001, 155, 101-112. [CrossRef]

89. Bastidas, R.J.; Valdivia, R.H. Emancipating Chlamydia: Advances in the Genetic Manipulation of a Recalcitrant Intracellular Pathogen. Microbiol. Mol. Biol. Rev. 2016, 80, 411-427. [CrossRef]

90. Wickstrum, J.; Sammons, L.R.; Restivo, K.N.; Hefty, P.S. Conditional Gene Expression in Chlamydia trachomatis using the Tet System. PLoS ONE 2013, 8, e76743. [CrossRef]

91. Ouellette, S.P. Feasibility of a Conditional Knockout System for Chlamydia Based on CRISPR Interference. Front. Cell. Infect. Microbiol. 2018, 8, 59. [CrossRef]

92. Yother, J.; Goguen, J.D. Isolation and characterization of Ca2 ${ }^{+}$-blind mutants of Yersinia pestis. J. Bacteriol. 1985, 164, 704-711. [PubMed] 
93. Fields, K.A.; Hackstadt, T. Evidence for the secretion of Chlamydia trachomatis CopN by a type III secretion mechanism. Mol. Microbiol. 2000, 38, 1048-1060. [CrossRef] [PubMed]

94. Jamison, W.P.; Hackstadt, T. Induction of type III secretion by cell-free Chlamydia trachomatis elementary bodies. Microb. Pathog. 2008, 45, 435-440. [CrossRef] [PubMed]

95. Betts-Hampikian, H.J.; Fields, K.A. The Chlamydial Type III Secretion Mechanism: Revealing Cracks in a Tough Nut. Front. Microbiol. 2010, 1, 114. [CrossRef]

96. Ferrell, J.C.; Fields, K.A. A working model for the type III secretion mechanism in Chlamydia. Microbes Infect. 2016, 18, 84-92. [CrossRef]

97. Lee, J.J.; Kim, D.G.; Kim, D.H.; Simborio, H.L.; Min, W.; Lee, H.J.; Her, M.; Jung, S.C.; Watarai, M.; Kim, S. Interplay between Clathrin and Rab5 Controls the Early Phagocytic Trafficking and Intracellular Survival of Brucella abortus within HeLa cells. J. Biol. Chem. 2013, 288, 28049-28057. [CrossRef]

98. Hower, S.; Wolf, K.; Fields, K.A. Evidence that CT694 is a novel Chlamydia trachomatis T3S substrate capable of functioning during invasion or early cycle development. Mol. Microbiol. 2009, 72, 1423-1437. [CrossRef]

99. Chen, Y.-S.; Bastidas, R.J.; Saka, H.A.; Carpenter, V.K.; Richards, K.L.; Plano, G.V.; Valdivia, R.H. The Chlamydia trachomatis Type III Secretion Chaperone Slc1 Engages Multiple Early Effectors, Including TepP, a Tyrosine-phosphorylated Protein required for the Recruitment of CrkI-II to Nascent Inclusions and Innate Immune Signaling. PLoS Pathog. 2014, 10, e1003954. [CrossRef]

100. Benaud, C.; Gentil, B.J.; Assard, N.; Court, M.; Garin, J.; Delphin, C.; Baudier, J. AHNAK interaction with the annexin 2/S100A10 complex regulates cell membrane cytoarchitecture. J. Cell Biol. 2004, 164, 133-144. [CrossRef]

101. Haase, H.; Pagel, I.; Khalina, Y.; Zacharzowsky, U.; Person, V.; Lutsch, G.; Petzhold, D.; Kott, M.; Schaper, J.; Morano, I. The carboxyl-terminal ahnak domain induces actin bundling and stabilizes muscle contraction. FASEB J. 2004, 18, 839-841. [CrossRef]

102. McKuen, M.J.; Mueller, K.E.; Bae, Y.S.; Fields, K.A. Fluorescence-Reported Allelic Exchange Mutagenesis Reveals a Role for Chlamydia trachomatis TmeA in Invasion That Is Independent of Host AHNAK. Infect. Immun. 2017, 85, e00640-17. [CrossRef] [PubMed]

103. Lee, I.H.; Lim, H.J.; Yoon, S.; Seong, J.K.; Bae, D.S.; Rhee, S.G.; Bae, Y.S. Ahnak Protein Activates Protein Kinase C (PKC) through Dissociation of the PKC-Protein Phosphatase 2A Complex. J. Biol. Chem. 2008, 283, 6312-6320. [CrossRef] [PubMed]

104. Belland, R.J.; Scidmore, M.A.; Crane, D.D.; Hogan, D.M.; Whitmire, W.; McClarty, G.; Caldwell, H.D. Chlamydia trachomatis cytotoxicity associated with complete and partial cytotoxin genes. Proc. Natl. Acad. Sci. USA 2001, 98, 13984-13989. [CrossRef] [PubMed]

105. Aktories, K.; Schwan, C.; Jank, T. Clostridium difficile Toxin Biology. Annu. Rev. Microbiol. 2017, 71, $281-307$. [CrossRef] [PubMed]

106. Chandrasekaran, R.; Lacy, D.B. The role of toxins in Clostridium difficile infection. FEMS Microbiol. Rev. 2017, 41, 723-750. [CrossRef]

107. Thalmann, J.; Janik, K.; May, M.; Sommer, K.; Ebeling, J.; Hofmann, F.; Genth, H.; Klos, A. Actin Re-Organization Induced by Chlamydia trachomatis Serovar D-Evidence for a Critical Role of the Effector Protein CT166 Targeting Rac. PLoS ONE 2010, 5, e9887. [CrossRef]

108. Bothe, M.; Dutow, P.; Pich, A.; Genth, H.; Klos, A. DXD Motif-Dependent and -Independent Effects of the Chlamydia trachomatis Cytotoxin CT166. Toxins 2015, 7, 621-637. [CrossRef]

109. Dennis, M.W.; Storz, J. Infectivity of Chlamydia psittaci of bovine and ovine origins for cultured cells. Am. J. Vet. Res. 1982, 43, 1897-1902.

110. Campbell, S.; Richmond, S.J.; Yates, P.S. The effect of Chlamydia trachomatis infection on the host cell cytoskeleton and membrane compartments. J. Gen. Microbiol. 1989, 135, 2379-2386. [CrossRef]

111. Grieshaber, S.S.; Grieshaber, N.A.; Hackstadt, T. Chlamydia trachomatis uses host cell dynein to traffic to the microtubule-organizing center in a p50 dynamitin-independent process. J. Cell Sci. 2003, 116, 3793-3802. [CrossRef]

112. Campbell, S.; Richmond, S.J.; Yates, P. The development of Chlamydia trachomatis inclusions within the host eukaryotic cell during interphase and mitosis. J. Gen. Microbiol. 1989, 135, 1153-1165. [CrossRef] [PubMed]

113. Derré, I.; Swiss, R.; Agaisse, H. The lipid transfer protein CERT interacts with the Chlamydia inclusion protein IncD and participates to ER-Chlamydia inclusion membrane contact sites. PLoS Pathog. 2011, 7, e1002092. [CrossRef] [PubMed] 
114. Dumoux, M.; Clare, D.K.; Saibil, H.R.; Hayward, R.D. Chlamydiae assemble a pathogen synapse to hijack the host endoplasmic reticulum. Traffic 2012, 13, 1612-1627. [CrossRef] [PubMed]

115. Beatty, W.L. Trafficking from CD63-positive late endocytic multivesicular bodies is essential for intracellular development of Chlamydia trachomatis. J. Cell Sci. 2006, 119, 350-359. [CrossRef]

116. Beatty, W.L. Late endocytic multivesicular bodies intersect the chlamydial inclusion in the absence of CD63. Infect. Immun. 2008, 76, 2872-2881. [CrossRef]

117. Robertson, D.K.; Gu, L.; Rowe, R.K.; Beatty, W.L. Inclusion biogenesis and reactivation of persistent Chlamydia trachomatis requires host cell sphingolipid biosynthesis. PLoS Pathog. 2009, 5, e1000664. [CrossRef]

118. Kumar, Y.; Valdivia, R.H. Actin and Intermediate Filaments Stabilize the Chlamydia trachomatis Vacuole by Forming Dynamic Structural Scaffolds. Cell Host Microbe 2008, 4, 159-169. [CrossRef]

119. Chin, E.; Kirker, K.; Zuck, M.; James, G.; Hybiske, K. Actin Recruitment to the Chlamydia Inclusion Is Spatiotemporally Regulated by a Mechanism That Requires Host and Bacterial Factors. PLoS ONE 2012, 7, e46949. [CrossRef]

120. Dong, F.; Su, H.; Huang, Y.; Zhong, Y.; Zhong, G. Cleavage of host keratin 8 by a Chlamydia-secreted protease. Infect. Immun. 2004, 72, 3863-3868. [CrossRef]

121. Savijoki, K.; Alvesalo, J.; Vuorela, P.; Leinonen, M.; Kalkkinen, N. Proteomic analysis of Chlamydia pneumoniae-infected HL cells reveals extensive degradation of cytoskeletal proteins. FEMS Immunol. Med. Microbiol. 2008, 54, 375-384. [CrossRef]

122. Nogueira, A.T.; Pedrosa, A.T.; Carabeo, R.A. Manipulation of the Host Cell Cytoskeleton by Chlamydia. Curr. Top. Microbiol. Immunol. 2018, 412, 59-80. [PubMed]

123. Todd, W.J.; Caldwell, H.D. The interaction of Chlamydia trachomatis with host cells: Ultrastructural studies of the mechanism of release of a biovar II strain from HeLa 229 cells. J. Infect. Dis. 1985, 151, 1037-1044. [CrossRef] [PubMed]

124. Lutter, E.I.; Barger, A.C.; Nair, V.; Hackstadt, T. Chlamydia trachomatis inclusion membrane protein CT228 recruits elements of the myosin phosphatase pathway to regulate release mechanisms. Cell Rep. 2013, 3, 1921-1931. [CrossRef] [PubMed]

125. Mital, J.; Miller, N.J.; Fischer, E.R.; Hackstadt, T. Specific chlamydial inclusion membrane proteins associate with active Src family kinases in microdomains that interact with the host microtubule network. Cell. Microbiol. 2010, 12, 1235-1249. [CrossRef] [PubMed]

126. Matsumura, F.; Hartshorne, D.J. Myosin phosphatase target subunit: Many roles in cell function. Biochem. Biophys. Res. Commun. 2008, 369, 149-156. [CrossRef] [PubMed]

127. Shaw, J.H.; Key, C.E.; Snider, T.A.; Sah, P.; Shaw, E.I.; Fisher, D.J.; Lutter, E.I. Genetic Inactivation of Chlamydia trachomatis Inclusion Membrane Protein CT228 Alters MYPT1 Recruitment, Extrusion Production, and Longevity of Infection. Front. Cell. Infect. Microbiol. 2018, 8, 415. [CrossRef]

128. Nguyen, P.H.; Lutter, E.I.; Hackstadt, T. Chlamydia trachomatis inclusion membrane protein MrcA interacts with the inositol 1,4,5-trisphosphate receptor type 3 (ITPR3) to regulate extrusion formation. PLoS Pathog. 2018, 14, e1006911. [CrossRef]

129. Volceanov, L.; Herbst, K.; Biniossek, M.; Schilling, O.; Haller, D.; Nölke, T.; Subbarayal, P.; Rudel, T.; Zieger, B.; Häcker, G. Septins Arrange F-Actin-Containing Fibers on the Chlamydia trachomatis Inclusion and Are Required for Normal Release of the Inclusion by Extrusion. MBio 2014, 5, e01802-14. [CrossRef]

130. Mostowy, S.; Cossart, P. Septins: The fourth component of the cytoskeleton. Nat. Rev. Mol. Cell Biol. 2012, 13, 183-194. [CrossRef]

131. Geneste, O.; Copeland, J.W.; Treisman, R. LIM kinase and Diaphanous cooperate to regulate serum response factor and actin dynamics. J. Cell Biol. 2002, 157, 831-838. [CrossRef]

132. Zhao, X.-H.; Laschinger, C.; Arora, P.; Szászi, K.; Kapus, A.; McCulloch, C.A. Force activates smooth muscle alpha-actin promoter activity through the Rho signaling pathway. J. Cell Sci. 2007, 120, 1801-1809. [CrossRef] [PubMed]

133. Zhao, L.; Chi, L.; Zhao, J.; Wang, X.; Chen, Z.; Meng, L.; Liu, G.; Guan, G.; Wang, F. Serum response factor provokes epithelial-mesenchymal transition in renal tubular epithelial cells of diabetic nephropathy. Physiol. Genom. 2016, 48, 580-588. [CrossRef] [PubMed]

134. Zhao, X.; He, L.; Li, T.; Lu, Y.; Miao, Y.; Liang, S.; Guo, H.; Bai, M.; Xie, H.; Luo, G.; et al. SRF expedites metastasis and modulates the epithelial to mesenchymal transition by regulating miR-199a-5p expression in human gastric cancer. Cell Death Differ. 2014, 21, 1900-1913. [CrossRef] [PubMed] 
135. Zadora, P.K.; Chumduri, C.; Imami, K.; Berger, H.; Mi, Y.; Selbach, M.; Meyer, T.F.; Gurumurthy, R.K. Integrated Phosphoproteome and Transcriptome Analysis Reveals Chlamydia-Induced Epithelial-to-Mesenchymal Transition in Host Cells. Cell Rep. 2019, 26, 1286-1302. [CrossRef] [PubMed]

136. Igietseme, J.U.; Omosun, Y.; Nagy, T.; Stuchlik, O.; Reed, M.S.; He, Q.; Partin, J.; Joseph, K.; Ellerson, D.; George, Z.; et al. Molecular Pathogenesis of Chlamydia Disease Complications: Epithelial-Mesenchymal Transition and Fibrosis. Infect. Immun. 2018, 86, e00585-17. [CrossRef] [PubMed]

137. Rajić, J.; Inic-Kanada, A.; Stein, E.; Dinić, S.; Schuerer, N.; Uskoković, A.; Ghasemian, E.; Mihailović, M.; Vidaković, M.; Grdović, N.; et al. Chlamydia trachomatis Infection Is Associated with E-Cadherin Promoter Methylation, Downregulation of E-Cadherin Expression, and Increased Expression of Fibronectin and

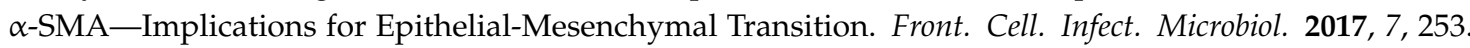
[CrossRef]

138. Thorpe, S.D.; Lee, D.A. Dynamic regulation of nuclear architecture and mechanics-A rheostatic role for the nucleus in tailoring cellular mechanosensitivity. Nucleus 2017, 8, 287-300. [CrossRef]

139. Lee, K.K.; Haraguchi, T.; Lee, R.S.; Koujin, T.; Hiraoka, Y.; Wilson, K.L. Distinct functional domains in emerin bind lamin A and DNA-bridging protein BAF. J. Cell Sci. 2001, 114, 4567-4573.

140. Guilluy, C.; Osborne, L.D.; Van Landeghem, L.; Sharek, L.; Superfine, R.; Garcia-Mata, R.; Burridge, K. Isolated nuclei adapt to force and reveal a mechanotransduction pathway in the nucleus. Nat. Cell Biol. 2014, 16, 376-381. [CrossRef]

141. Ho, C.Y.; Jaalouk, D.E.; Vartiainen, M.K.; Lammerding, J. Lamin A/C and emerin regulate MKL1-SRF activity by modulating actin dynamics. Nature 2013, 497, 507-511. [CrossRef]

142. Plessner, M.; Melak, M.; Chinchilla, P.; Baarlink, C.; Grosse, R. Nuclear F-actin formation and reorganization upon cell spreading. J. Biol. Chem. 2015, 290, 11209-11216. [CrossRef] [PubMed]

143. Kim, M.; Ogawa, M.; Mimuro, H.; Sasakawa, C. Reinforcement of epithelial cell adhesion to basement membrane by a bacterial pathogen as a new infectious stratagem. Virulence 2010, 1, 52-55. [CrossRef] [PubMed]

144. Kim, M.; Ogawa, M.; Fujita, Y.; Yoshikawa, Y.; Nagai, T.; Koyama, T.; Nagai, S.; Lange, A.; Fässler, R.; Sasakawa, C. Bacteria hijack integrin-linked kinase to stabilize focal adhesions and block cell detachment. Nature 2009, 459, 578-582. [CrossRef] [PubMed]

(C) 2019 by the authors. Licensee MDPI, Basel, Switzerland. This article is an open access article distributed under the terms and conditions of the Creative Commons Attribution (CC BY) license (http://creativecommons.org/licenses/by/4.0/). 